\title{
No âmago da africanização: pessoas negras e de cor nos mapas populacionais do Maranhão colonial (1798-1821)
}

\author{
Antonia da Silva Mota* \\ Maísa Faleiros da Cunha*
}

0 estudo analisa o "boom" demográfico das populações escravas de origem africana nas áreas de plantation a partir dos Mapas Estatísticos do Maranhão. Em especial, focalizamos a freguesia do Rosário do Itapecuru utilizando outras fontes documentais - inventários post mortem e registros paroquiais de batismo. Os Mapas de 1798 e 1821 possibilitaram evidenciar o perfil sexual, etário, étnico e a condição jurídica da população, mostrando a importância da população escrava nas áreas de cultivo do algodão e arroz, que chegava a quase $80 \%$ dos residentes. Essas populações, por sua vez, guardavam algumas particularidades em relação a outras áreas de plantation do Estado do Brasil, como, por exemplo, a razão de sexo marcada pela quase paridade entre homens e mulheres.

Palavras-chave: Escravidão. Mapas de população. Maranhão.

\footnotetext{
*Universidade Federal do Maranhão, Departamento de História (UFMA), São Luís-MA, Brasil (motaufma@gmail.com).

** Núcleo de Estudos de População “Elza Berquó” (Nepo), Universidade Estadual de Campinas (Unicamp), Campinas-SP, Brasil (maisa_cunha@yahoo.com.br).
} 


\section{Introdução}

No estado do Grão-Pará e Maranhão importantes mudanças se deram na segunda metade do século XVIII, quando a Coroa portuguesa decidiu finalmente explorar suas potencialidades. Vários estudiosos já ressaltaram as mudanças ocorridas na porção setentrional da América portuguesa sob a injunção do Marquês de Pombal e da Companhia Geral de Comércio do Grão-Pará e Maranhão. Segundo Charles Boxer (2002, p. 194), tal direcionamento decorreu da conjuntura de depressão econômica com a "queda vertical na produção do ouro brasileiro e as crises recorrentes no comércio do açúcar, no tráfico de escravos e na exploração das minas de diamante”. Com o agravamento das finanças em função das pesadas despesas advindas do envolvimento de Portugal na Guerra dos Sete Anos, medidas drásticas foram tomadas pelo ministério pombalino no sentido de reduzir a dependência econômica do Império, imposta pela importação de produtos manufaturados e de matérias-primas de Portugal e suas colônias.

Jobson de Arruda (1980, p. 641) assinala que, no âmbito do programa político posto em prática, "o incremento da agricultura foi um dos itens principais das reformas implantadas sob sua influência direta [do ministro Pombal]. 0 cultivo do algodão, do arroz, do anil, do café e do cacau espalhou-se rapidamente por toda a extensão do território brasileiro". Contudo, as medidas de maior efeito para sanear as finanças foram as direcionadas para exploração do território formado pelo Estado do Grão-Pará e Maranhão. Segundo Luiz Felipe de Alencastro (2000, p. 142):

Arma-se uma grande operação destinada a alterar as variáveis econômicas e sociais da região para melhor enquadrá-la no sistema atlântico e no controle metropolitano. Leis régias proíbem definitivamente o cativeiro indígena, ao passo que a agricultura comercial é estimulada. Subsídios fiscais são concedidos às duas Capitanias do Norte e uma nova empresa monopolista, a Companhia de Comércio do Grão-Pará e Maranhão, açambarca os produtos de importação, ganhando ainda o trato de negros de Angola e da Guiné para o litoral amazonense entre 1775 e 1778.

Vencida a oposição inicial dos pequenos comerciantes, seriamente prejudicados com as medidas de caráter monopolista, a Companhia Geral de Comércio do Grão-Pará e Maranhão passou a canalizar o comércio marítimo da região. Resumindo os compêndios já escritos sobre a intervenção pombalina, Charles Boxer (2002, p. 205) aponta:

Entre 1757 a 1777, foram importados 25.365 negros para o Pará e Maranhão, provenientes dos portos da África Ocidental, principalmente de Cacheu e Bissau, na Guiné portuguesa, locais até então com importância relativamente pequena no comércio escravista transatlântico. Para ajudar os colonos a comprar escravos negros a crédito de longo prazo, a taxa de juros original foi diminuída de $5 \%$ para $3 \%$, e por fim abolida de vez, os escravos eram vendidos então pelo preço de custo cobrado na África Ocidental, acrescido de pequena taxa referente ao transporte.

Além das facilidades para obtenção de mão de obra escrava, a Companhia de Comércio adiantou capitais sob a forma de dinheiro e ferramentas agrícolas para serem reembolsados 
pelos plantadores depois de um ou mais anos. A nova fronteira agrícola acabou atraindo para a região uma leva de imigrantes desejosos de se tornarem proprietários rurais, o que pode ser verificado pelas emissões de Cartas de Sesmarias. No período de atividade da Companhia (1755 a 1777), foram distribuídos 50 títulos de terra. Este número aumenta para 450 doações de terras entre 1792 e 1798, comprovando o intenso processo de ocupação do território no período mencionado (MOTA, 2012, p. 109).

Apoiados nas informações coletadas pelo banco de dados do Tráfico Transatlântico, cuja base para o Maranhão ficou a cargo de Walter Hawthorne, bem como nos Mapas Gerais de População e em estimativas feitas na época, o historiador Matthias Assunção calculou em 114.000 o número de africanos que entraram no porto de São Luís entre 1755 e 1820. Apesar de os números serem significativos, os estudiosos calculam um erro de $20 \%$ para baixo, pois acreditam que muito mais escravizados devem ter sido trazidos para as terras maranhenses neste período (ASSUNÇÃO, 2015, p. 447).

Um fator conjuntural contribuiu ainda mais para o desenvolvimento da agricultura na capitania do Maranhão, sendo "estimulada pela Independência americana, que forçou a Grã-Bretanha a se voltar para a América portuguesa com vista a obter o algodão que, até o início desse evento, ia buscar nas colônias norte-americanas” (BOXER, 2002, p. 206). Os autores que estudaram este período, referidos anteriormente, além do algodão, assinalaram também o sucesso de outro produto agrícola introduzido na região: o arroz branco da Carolina. Imposto aos fazendeiros sob pesadas sanções em substituição à variedade local avermelhada, este produto, de alta qualidade, era exportado quase sem nenhuma taxa alfandegária e ainda sem concorrência no mercado europeu. Logo esta capitania "estava produzindo arroz suficiente para satisfazer toda a procura da metrópole, e um excedente substancial era reexportado de Lisboa para Londres, Roterdã, Gênova, Marselha e outros lugares" (BOXER, 2002, p. 206).

Os resultados não tardaram a aparecer e o crescimento das exportações já era patente entre 1760 e 1778, quando seu movimento duplicou: "em termos absolutos, o comércio de exportação do Maranhão passou de 1055 contos, em 1796, para 1776 contos, em 1807. O superávit é constante. A ascensão é notável a partir de 1799 e traça uma linha quase vertical a partir de 1801" (ARRUDA, 1980, p. 628).

As políticas de fomento agrícola do ministério pombalino diversificaram a produção, o que levou à breve conjuntura de prosperidade verificada nas últimas décadas do período colonial, em que o Estado do Grão-Pará e Maranhão teve papel fundamental com a exportação de novos produtos. Ainda mais, para Arruda (1980, p. 620), "o metal precioso deixava de ser a mola mestra da economia portuguesa [...] o final do século XVIII, marca o nascimento da exploração do café, cacau, algodão e o arroz".

A diversificação produtiva começava já na própria região, em que, sob a rígida supervisão do governador Joaquim de Melo e Póvoas (1761 a 1779), "sobrinho" do Marquês de Pombal, o potencial de exportação das capitanias foi ampliado ao máximo. Conforme Barroso (2009, p. 83), alguns artigos de exportação eram de origem extrativista, "como 
as toras de madeira e as varas; outros, resultado de um trabalho mais elaborado como os atanados (couros bovinos mais espessos) e as vaquetas (couro fino para vestimentas e outros objetos) e ainda, aqueles resultantes da produção agrícola como o café, o gergelim, o cacau, o algodão e o arroz". Sobre o volume de exportação, o autor cita que, em 1788 , foram embarcadas "quase 57 mil arrobas de arroz (equivalente a aproximadamente 4.607.000 quilos) e 63.500 mil arrobas de algodão (equivalente a quase 93.597 quilos)" (BARROSO, 2009, p.83).

A conjuntura de prosperidade econômica na capitania do Maranhão durou pouco mais de quatro décadas, pois já no início do século XIX não conseguiu mais os resultados verificados no período áureo da exportação. Concomitante ao incremento econômico, a administração metropolitana passou a estimular a feitura de contagens populacionais, importante para controle das políticas de incentivo e cobrança de impostos.

\section{Os Mapas Estatísticos da capitania do Maranhão}

O objetivo maior de nossa pesquisa é dar visibilidade a um fator determinante ocorrido com a inserção das possessões portuguesas setentrionais ao mercado Atlântico: a "africanização" das áreas de cultivo via entrada massiva de populações escravizadas. Tal fenômeno se evidencia nos Mapas Estatísticos da Capitania do Maranhão do período final da colônia, notadamente nos manuscritos referentes a 1798, disponibilizados on line pela Biblioteca Nacional Digital, e os de 1801, que se encontram depositados na Biblioteca Pública Benedito Leite, em São Luís/MA. Também é possível verificar tal fenômeno social na obra Estatística histórico-geográfica da Província do Maranhão, de Antônio Bernardino Pereira do Lago, em que se encontram, anexas ao texto, as totalizações extraídas dos Mapas Estatísticos feitos em 1821, que permitem saber a população geral da capitania, assim como de todas as freguesias e povoações de índios domésticos.

A riqueza de informações contidas nos Mapas Gerais de População produzidos no período colonial é significativa, ainda que seja impossível não notar suas imperfeições. A documentação apresenta falhas quanto à sua abrangência, uma vez que nem todos os habitantes foram contados, e também quanto às categorias adotadas na classificação dos habitantes no que se refere à cor, fundamental para o entendimento daquela formação social. Nos Mapas, a população foi dividida em três grandes segmentos, conforme a cor: "brancos", "pretos" e "mulatos". Os dois últimos eram ainda diferenciados quanto à condição jurídica: livres e cativos. Apresentavam-se também repartidos entre homens e mulheres e por faixa etária: 0 a 5, 5 a 10 e, a partir daí, em casas decimais até os 100 anos. 0 problema maior reside na categorização da cor, pois os que não eram "brancos" nem "pretos" foram classificados como "mulatos", quando sabemos que a presença dos indígenas se fazia notar em todos os lugares habitados, ainda que parte deles tenha aparecido nos Mapas Gerais contados à parte. Vemos as dificuldades de enquadramento dos que realizaram a contagem na anotação apresentada a seguir, que consta no Mapa geral da capitania: 
As três classes de Habitantes não se podem apurar, por mais escrupulosa que seja a inquirição; porquanto há Mulatos quase Brancos, Mamelucos que precedem de Branco e índio, Cafuzos de Mulato e Preto; e mestiços de Preto e Índio, e que facilmente confundem para a classe mais aproximada de que precedem. Os índios dispersos, por não estarem em suas Povoações, vão na classe dos Mulatos nas Paróquias. (BIBLIOTECA PÚBLICA BENEDITO LEITE, 1801) ${ }^{1}$

Observamos, pelo trecho citado, que a realidade local não cabia no formulário enviado para todo o Império português, pois significa uma grave distorção contabilizar "índio disperso" como "mulato", supostamente uma categoria que se refere às populações afrodescendentes. Quanto à "clivagem social e jurídica da América portuguesa”, explicitada na forma de enquadrar a população e tendo a cor como distinção, o historiador Sérgio Nadalin adverte que era passível de erro tanto para "os de cor", como para os considerados "brancos":

Na escala social, estes [os "de cor"] estavam distantes da camada "branca" da sociedade colonial brasileira. Todavia, é necessário grifar que, como "branco" era muito mais uma categoria social do que "cor" da pele, o "branqueamento" do pardo sempre era possível, dependendo de certas condições relacionadas, principalmente, a um eventual aumento da riqueza. (NADALIN, 2004, p. 56)

Os estudiosos concordam que as categorias raciais contidas nesses Mapas representam uma "construção social”; seguimos a análise de Assunção (2015), que considera que havia uma distinção significativa entre os brancos e os outros segmentos da população, no caso, as pessoas “de cor”, denominados nos Mapas de "pretos" e “mulatos". No entanto, lembra o autor, a condição jurídica pesava mais na hierarquia social, isto é, a distinção entre livres e cativos.

Outro problema encontrado pelo elaborador dos Resumos dos Mapas refere-se aos casamentos "interétnicos" verificados então, resolvidos pelos párocos com a separação dos casais, contabilizando-os individualmente em uma e outra "classe", como ele mesmo afirmou: "nas contas dos casados se acham alguns em número ímpar, por haverem casado de umas com outras classes [por exemplo, cativos com libertos], e também por estarem ausentes alguns deles" (BIBLIOTECA PÚBLICA BENEDITO LEITE, 1801). Na contagem feita dois anos antes na capitania do Maranhão, em 1798, cujos originais estão disponíveis no site da Biblioteca Nacional, foram feitos levantamentos em dez freguesias e oito lugares de índios domésticos, mesmo número das paróquias e lugares contados em 1801. Apesar das falhas, é possível trabalhar com as contagens feitas sob a injunção das medidas centralizadoras do esclarecido Pombal, extraindo delas evidências importantes acerca da população residente, dessa forma chegando a seu perfil sexual, etário, étnico e condição jurídica.

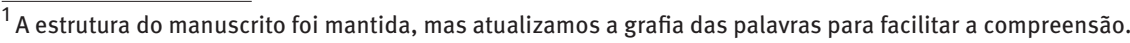




\section{Os Mapas Estatísticos de 1798 e 1821, análise comparativa}

A população da capitania do Maranhão, antes composta por uma maioria de índios e mestiços e raríssimos brancos, se modificou abruptamente, como visto anteriormente, com a importação massiva de mão de obra vinda do continente africano. A nova configuração social se manifesta na primeira década do século XIX.

A Tabela 1 mostra o aumento da população no período focalizado, principalmente o rápido crescimento do contingente classificado como "de cor", que mais que dobrou, enquanto os considerados "brancos" diminuíram em termos absolutos e relativos. A população total cresceu a uma taxa de $2,44 \%$ ao ano, no período $1777-1798$, e $2,92 \%$ a.a., entre 1798 e 1821 (ASSUNÇÃO, 2015, p. 439). Tal movimento populacional ocasionou taxas de crescimento elevadas na população total, constatadas pelas contagens feitas por párocos e funcionários régios. As estimativas dos Mapas dão conta de que, em 1777, a capitania possuía 47.410 habitantes, chegando a 78.694 em 1798 e a 152.634 pessoas em 1821.

TABELA 1

População da capitania do Maranhão, segundo cor e condição jurídica - 1798-1821

\begin{tabular}{|c|c|c|c|c|}
\hline \multirow{2}{*}{$\begin{array}{l}\text { Cor e condição } \\
\text { jurídica }\end{array}$} & \multicolumn{2}{|c|}{1798} & \multicolumn{2}{|c|}{1821} \\
\hline & $\mathrm{N}$ & $\%$ & $\mathrm{~N}$ & $\%$ \\
\hline Brancos & 24.273 & 30,8 & 23.994 & 15,7 \\
\hline Pretos livres & 1.332 & 1,6 & 9.308 & 6,0 \\
\hline Pretos cativos & 30.639 & 38,9 & 77.954 & 51,0 \\
\hline Mulatos livres & 12.288 & 15,6 & 25.111 & 16,4 \\
\hline Mulatos cativos & 6.238 & 7,9 & 6.580 & 4,3 \\
\hline Índios domésticos & 3.924 & 4,9 & 9.687 & 6,3 \\
\hline Total & 78.694 & 100 & 152.634 & 100 \\
\hline
\end{tabular}

Fonte: Biblioteca Pública Benedito Leite. Mapas estatísticos da capitania do Maranhão dos anos 1798 e 1821 . Seção Manuscritos.

Os escravizados de origem africana representavam 47\% da população em 1798 e já correspondiam a mais da metade dos residentes, em 1821, dividindo-se entre "pretos" e "mulatos". Portanto, o contingente de cor era a maioria nos dois momentos, sendo que os cativos chegavam a 55,3\%, em 1821, significando "a maior porcentagem de escravizados da população nas possessões portuguesas nas Américas” (ASSUNÇÃO, 2015, p. 439).

A partir da distribuição dos moradores pelas freguesias, é possível inferir também que, em 1798, a população da capitania se concentrava basicamente na llha do Maranhão e seu entorno: Baixo Itapecuru (Rosário) e litoral próximo (Alcântara). Fora deste espaço geográfico, onde se encontravam $62,9 \%$ da população, havia ainda contingente considerável de pessoas $(9,5 \%)$ no Sul e Médio Itapecuru (vila de Caxias), microrregião localizada na confluência dos rios Parnaíba e Itapecuru e na rota das boiadas que abasteciam as áreas açucareira e mineira (ASSUNÇÃO, 2015, p. 414). 
FIGURA 1

Detalhe do Mapa Geográfico da Província do Maranhão - 1855

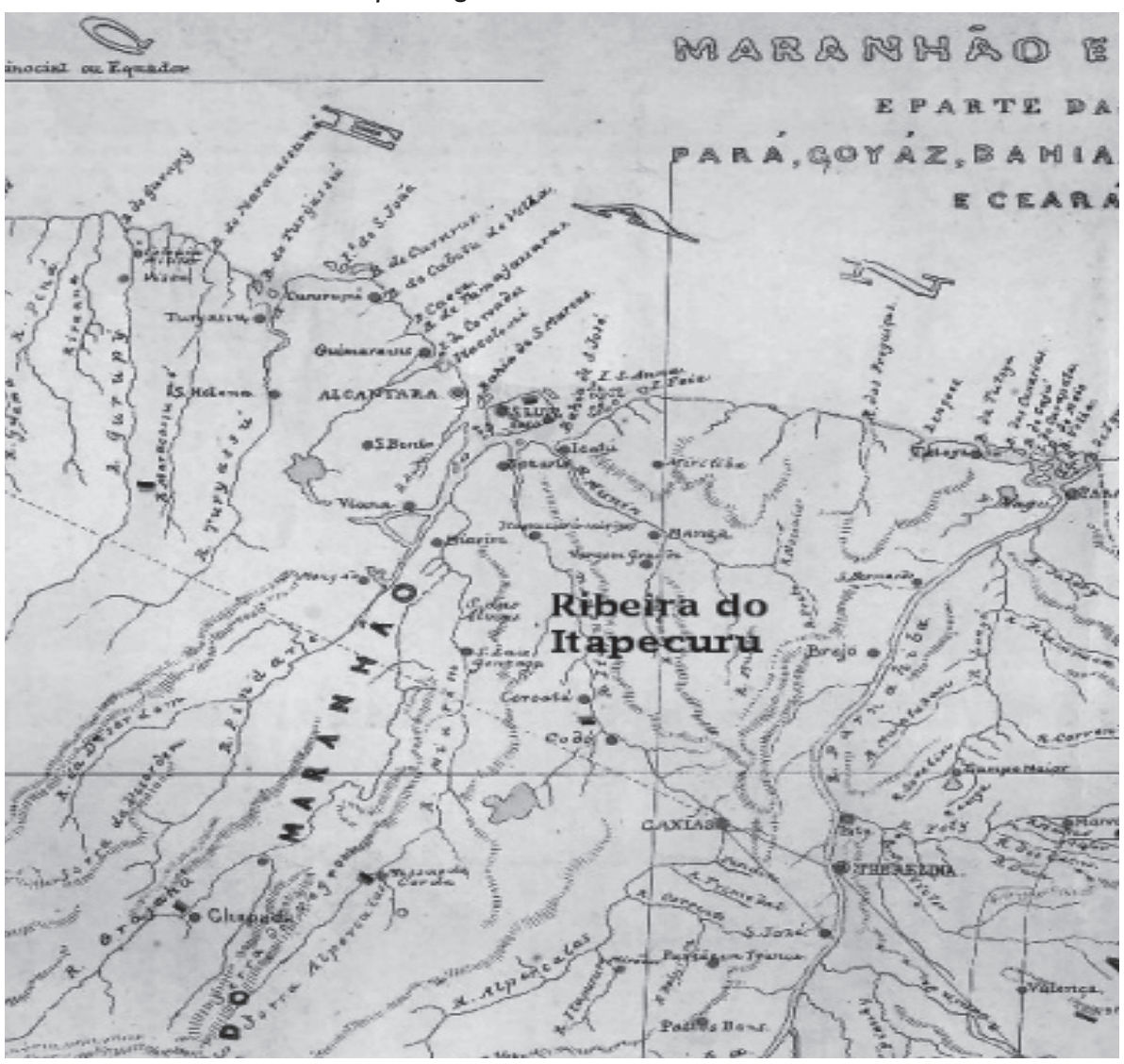

Fonte: Biblioteca Nacional do Rio de Janeiro. Carta corográfica das províncias do Maranhão, Piauí e parte das do Pará, Goiás, Bahia, Pernambuco e Ceará. Rio de Janeiro, 1855.

Em 1821, foram recenseadas 23 freguesias, sendo duas na área urbana da ilha de São Luís: as de N. S. da Conceição e N. S. da Vitória, que juntas totalizavam 19.611 habitantes, onde vivia a maioria dos considerados "brancos". Ainda nesse "Mapa", o de 1821, observamos que as áreas de ocupação inicial já apresentavam certa estagnação, avançando o povoamento para áreas próximas, como as vilas de Guimarães e Viana. A população também continuava a crescer naquelas áreas mais distantes com o início de lavouras para agroexportação, ainda que localizadas longe do núcleo inicial, como o Baixo Parnaíba (vila de São Bernardo), o Médio Itapecuru (vila de Caxias) e o sul (Pastos Bons), que já alcançavam 48,9\% da população (ASSUNÇÃO, 2015, p. 415).

\section{A Ribeira do Itapecuru, a paróquia do Rosário}

A distribuição da população pelas freguesias nos dois momentos mostra que a paróquia N. S. do Rosário do Itapecuru era a que concentrava maior população oriunda do continente 
africano. A microrregião do Baixo Itapecuru possuía diferenças bem pronunciadas se comparada com as áreas mais afastadas do território maranhense, como foi descrito no relatório do engenheiro-mor Francisco de Paula Ribeiro, que passou pela região em 1819, com a missão de definir fronteiras entre as capitanias limítrofes do Maranhão e Goiás. Ao se referir às vilas de Rosário e Itapecuru-Mirim, o funcionário régio mencionou que:

Juntam-se nele pelas principais festas anuais a maior parte dos lavradores do distrito, quando em tais ocasiões se não acham nas suas casas da cidade do Maranhão, aonde de ordinário passam uma boa parte do ano. 0 resto do tempo é este lugar insípido e triste, apesar da contínua escala que nele fazem todas as embarcações que navegam este rio, ou seja, para cima ou para baixo, especialmente as que vão ou vêm da vila de Caxias. Itapecuru-Mirim, segundo lugar notável deste mesmo rio, [...] tem pouco mais ou menos 320 fogos. São térreos os seus edifícios, feitos de madeira e barro, cobertos de telhas alguns, e os mais cobertos de palha de palmeira, a que chamam pindoba. As ruas não são bem reguladas, porém em melhor arrumação do que as do lugar do Rosário, e tem unicamente uma capela ainda não bem-acabada. São europeus pela maior parte os seus habitantes estabelecidos ali com lojas de fazendas secas ou molhadas: todo o resto é gente pobre, e vive miseravelmente. Não tem espécie alguma de lavoura, ainda mesmo entre os últimos para manter-se, assim por natural indolência sua, como porque a natureza estéril daquele pedaço de terreno arenoso a ela não os convida. Vivem como os da freguesia do Rosário de tudo o que lhe vem do Maranhão [São Luís] 30 léguas distante, à exceção do artigo carnes verdes, ou ainda secas, durante o tempo em que descem os gados dos sertões da capitania. Neste lugar se ajuntam todos os anos, desde janeiro até julho, as boiadas que desta capitania e da do Piauí vêm a vender-se em feira aos contratadores do talho público da capital, ou aos lavradores do Itapecuru, que para o sustento das suas escravaturas compram a maior parte. (RIBEIRO, 2002, p. 71)

Relevando o juízo de valor, o relato mostra a importância desse espaço geográfico, localizado na confluência da zona de criação de gado e das lavouras de algodão e arroz. 0 memorialista apontou ainda a concentração de riqueza advinda do sistema agroexportador e a marginalização dos moradores pobres livres e libertos, em especial os das vilas de Rosário e Itapecuru Mirim, que, provavelmente sem terras e sem capital, sobreviviam à margem dos negócios agrícolas e mercantis. Sobretudo, indica a influência que sofria essa região com relação à cidade portuária de São Luís, onde moravam os grandes proprietários rurais e comerciantes.

Também é relevante a contagem feita em 1801, ainda que menos habitantes tenham sido contabilizados pelos párocos. José Vicente Serrão (1998, p. 43) referiu-se a essa contagem populacional, afirmando que, "quanto à quantidade e à qualidade das fontes disponíveis, só em 1801 se produziu em Portugal, por iniciativa de Rodrigo de Sousa Coutinho e José Antonio de Sá, um recenseamento geral da população que se pode considerar minimamente fiável". Nos Mapas produzidos a partir dessa chamada, para a capitania do Maranhão foi anotado que párocos de localidades importantes, como as da "Cidade de São Luís e as vilas de Alcântara, Guimarães e Icatu”, não tinham enviado suas totalizações. Supostamente a falha se verificou ante o temor da população de que tais levantamentos servissem para incrementar o fisco e o recrutamento dos homens solteiros para as milícias. 
Mesmo assim, várias paróquias importantes foram recenseadas. Para os objetivos de nossa pesquisa interessam particularmente as totalizações das vilas mais próximas da Ilha de São Luís, onde foram implantadas as fazendas de algodão e arroz e para onde foi levada a maior parte dos escravizados vindos de África (BIBLIOTECA PÚBLICA BENEDITO LEITE, 1801).

Constatamos que, nos Mapas de 1801, foram escrituradas características de 36.126 pessoas, portanto, menos pessoas foram encontradas, pois nos Mapas de 1798 os contabilizados correspondiam a 78.694! Mesmo assim, consideramos importante analisar a contagem de 1801, em que brancos, índios, "pretos" e "mulatos" livres somavam 52,17\% do total, enquanto aqueles vivendo sob a condição escrava representavam 47,83\% dos habitantes. 0 boom econômico se fez sentir, sobretudo, nas áreas ligadas à agroexportação, onde as populações escravizadas africanas e afrodescendente se concentravam; a saber, na "Ilha do Maranhão" e em suas proximidades, notadamente na paróquia de Nossa Senhora do Rosário do Itapecuru. No entanto, foi detectada também a presença de tais populações nas paróquias de N. S. de Nazaré da Ribeira do Mearim, na de Viana, de N. S. da Conceição e São Bernardo da Parnaíba, de N. S. da Conceição e São José de Aldeias Altas e de São Bento das Balsas em Pastos Bons, ainda que em menor proporção.

Nos testamentos da região aparece com muita nitidez a presença de tais populações e as diferenciações feitas quanto à origem dos mesmos, mesclando informações sobre lugar de nascimento, cor, idade e condição física. Observamos fortes marcas de tal processo de africanização nas últimas vontades do casal Bernardes José Teixeira, quando por escrito determinaram a forma como dividiram a fortuna familiar:

Declaramos que temos dado a nossa filha Ivana Maria de Castro os escravos seguintes do Gentio da Guiné = Bento e Bonifácio, que custaram duzentos e quarenta mil réis = Rodrigo, que custou sessenta = Dionísia com sua mãe, que custaram duzentos mil réis. Demos mais a dita nossa filha, sete escravos crioulos, que os rematamos em praça, que foram dos Padres JESUÍTAS, cuja importância consta do auto de Rematação, e são os escravos seguintes $=$ Jacinto, e sua mulher Micaela com cinco filhos $=$ Declaramos que demos a nossa filha Maria Josefa de Castro seis escravos do Gentio da Guiné todos em preço de cento e vinte mil réis; Demos-lhe mais uma preta crioula em preço de cento e trinta mil reis $=$ Declaramos que fizemos uma escritura de Patrimônio ao nosso Filho José Bernardes de Castro para se ordenar de sacerdote, que agora não teve efeito, somente está o dito nosso filho entregue de quatro escravos, que são os seguintes = Dionísio e Miguel, seu filho Mulato, Jeronimo Mulato, sua mulher Luciana do Gentio de Guiné com uma cria, todos em preço de quatrocentos e oitenta mil reis = Declaramos, que possuímos um escravo mulato por nome Pedro Sapateiro, o qual está em poder de Francisca Xavier Pereira pela criação que lhe deu, falecida que seja, meus testamenteiros tomarão conta dele. (APEM, Livro de Registro de Testamento, 1770, fl. 346)

Essa fonte sempre é mais rica, pois mescla informações contábeis com referências às relações familiares na repartição das heranças, transmissão do patrimônio. Percebemos que o casal viveu entre as duas conjunturas pelas quais passou o antigo estado do Grão-Pará e Maranhão e, ao fazer testamento, no final da vida, já indicava claramente distinções na 
comunidade escrava: assinalou os "pretos”, “crioulos" e "mulatos”; mais refinado ainda, já diferenciava entre os gentios da Guiné e os nacionais.

Estudo realizado a partir de inventários post mortem de proprietários dão conta de escravarias compostas basicamente por africanos e seus filhos, dados como "crioulos". Uma amostragem construída com dados retirados de 26 desses documentos (1785-1825), a maioria pertencente a fazendeiros de algodão e arroz do Baixo Itapecuru, aponta que $55 \%$ dos cativos foram dados como africanos de "nações" diversas e outros $42 \%$ constavam como "crioulos", majoritariamente seus filhos, menores de 14 anos. Entre os 2.956 cativos arrolados nessa amostragem também aparecem os "mulatos", mas eles eram apenas $2 \%$ do total; existiam ainda referências a "cafuzos", mas em ínfimas proporções (MOTA, 2015, p. 183). Comparados aos Mapas de população, os inventários post mortem apresentam dados mais aproximados quanto à origem étnica, pois era importante para a avaliação dos comissários que deviam chegar ao preço do cativo, levando em conta sua origem, idade, sexo e as doenças que porventura tivessem.

No tempo da Companhia Geral de Comércio do Grão-Pará e Maranhão (1755-77), os escravizados eram denominados genericamente de "gentio da Guiné" ou de "Cacheu”, os dois principais portos de embarque de escravizados para o Norte. Mais à frente, no final dos setecentos, os espólios já demonstram o avanço do conhecimento dos avaliadores sobre os grupos étnicos trazidos para o Maranhão, uma vez que as listas passaram a indicar inúmeras outras denominações referentes à origem. Na amostra mencionada, sobressaíram os dados como "angola", que perfizeram $12 \%$, e os "mandinga" (9\%); aparecendo em menor porcentagem estão os "bijagós”, “minas” e "Caxeus” (4\%), seguidos de inúmeras outras designações étnicas com menos indivíduos representados (MOTA, 2015, p. 199), como se observa na Tabela 2.

TABELA 2

Escravizados, segundo origem étnica Ribeira do Itapecuru - 1785/1825

\begin{tabular}{lcc}
\hline \multicolumn{1}{c}{ Origem étnica } & N & $\%$ \\
\hline Angola & 321 & 12,0 \\
Mandinga & 257 & 9,0 \\
Caxeu & 121 & 4,0 \\
Bijago & 118 & 4,0 \\
Mina & 113 & 4,0 \\
Cabinda & 66 & 2,0 \\
Balanta & 61 & 2,0 \\
Moçambique & 53 & 2,0 \\
Fulupo & 50 & 2,0 \\
Benguela & 47 & 2,0 \\
Congo & 44 & 2,0 \\
Guiné & 37 & 1,0 \\
Papel & 32 & 1,0 \\
Baiuno & 23 & 1,0 \\
Fula & 20 & 1,0 \\
Mulato & 51 & 2,0 \\
Crioulo & 864 & 32,0 \\
\hline
\end{tabular}

Fonte: Arquivo do Tribunal de Justiça do Maranhão (1825). 
As "nações" que aparecem nos inventários post mortem maranhenses pouco divergem daquelas encontradas por Karasch (2000) em seu estudo para o Rio de Janeiro e Goiás; obviamente que em proporções diferentes. Tais denominações indicam portos de exportação de cativos ou vastas regiões específicas em África (KARASCH, 2000, p. 132). A Tabela 2 mostra que, para as possessões portuguesas ao norte do Brasil, foram trazidos grupos étnicos tanto da África Ocidental, os "vulgarmente chamados sudaneses", entre eles os mandinga, quanto os angola, do centro-ocidental do continente, os chamados "bantos", conforme designação citada por João José Reis (2003, p. 308). Além destas “nações” africanas aparecem identidades nacionais, como os crioulos, que nos inventários maranhenses eram majoritariamente os filhos dos cativos, menores de 14 anos, portanto, africanos de primeira geração. Outra particularidade: os mulatos eram apenas $2 \%$ nessa tipologia documental, contrastando com sua importância nos Mapas de população, em que foram designados "mulatos" todos os não "brancos" ou "pretos". Obviamente que o sentido com que aparece nos arrolamentos mencionados é mais fidedigno, representando o resultado do intercurso sexual de pessoas negras ou de cor com brancos.

Nos Mapas da capitania produzidos em 1801, nos interessa sobremaneira a paróquia de Nossa Senhora do Rosário do Itapecuru, onde, de um total de 14.000 pessoas contadas, os "pretos" e os supostamente "mulatos" totalizavam 13.177, mais de $94 \%$ da população! A elevada presença de populações africanas e afrodescendentes era espantosa para uma região amazônica, sendo que tal perfil se explica pela concentração de fazendas que cultivavam algodão e arroz para exportação.

TABELA 3

População, segundo a cor

Paróquia N. S. do Rosário do Itapecuru - 1801

\begin{tabular}{|c|c|c|}
\hline Cor & $\mathrm{N}$ & $\%$ \\
\hline Brancos & 823 & 5,9 \\
\hline Pretos & 8.302 & 59,3 \\
\hline Mulatos & 4.875 & 34,8 \\
\hline Total & 14.000 & 100,0 \\
\hline
\end{tabular}

Fonte: Biblioteca Pública Benedito Leite. Mapas estatísticos da capitania do Maranhão. São Luís (1801).

Crônicas regionais oitocentistas indicam que toda "a freguesia de N. S. do Rosário compreendia 196 fazendas, 226 sítios, 333 agricultores, 27 negociantes, 52 artistas ${ }^{2}$, além dos mais indivíduos brancos e forros de um e outro sexo, tem mais de 10.179 escravos" (MARQUES, 1970, p. 597). Ainda que aponte a significativa porcentagem de escravizados na paróquia, os dados do cronista divergem um pouco dos Mapas enviados a Lisboa, o que talvez se deva ao desmembramento da grande freguesia do Rosário, realizado em 1802. Mesmo assim, ficou o registro da concentração de unidades produtivas rurais nas proximidades de São Luís.

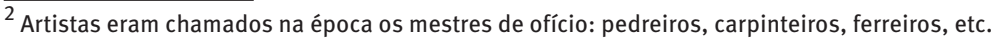


Precisando melhor as características da população da paróquia de N. S. do Rosário, o vigário registrou que 7.479 (62\%) eram cativos. A Tabela 4 mostra a distribuição dessa população por sexo e grupos etários.

TABELA 4

População cativa, por sexo, segundo grupos etários

Paróquia N. S. do Rosário - 1801

\begin{tabular}{lccccc}
\hline Grupos etários & Homens & Mulheres & Total & $\%$ & Razão de sexo \\
\hline 0-14 anos & 1.315 & 1.283 & 2.598 & 34,73 & 102,4 \\
15-50 anos & 2.057 & 2.062 & 4.119 & 55,07 & 99,7 \\
Mais de 50 anos & 378 & 384 & 762 & 10,17 & 98,4 \\
Total & 3.750 & 3.729 & 7.479 & 100,00 & \\
\hline
\end{tabular}

Fonte: Biblioteca Pública Benedito Leite. Mapas estatísticos da capitania do Maranhão. São Luís (1801).

Os dados revelam uma particularidade da região: a razão de sexo mostra que havia uma quase igualdade entre homens e mulheres. A razão de masculinidade no geral entre os cativos, em que os homens somavam 3.750 e as mulheres 3.729 , correspondia a 100,6, índice sui generis para áreas de grande lavoura, onde quase sempre os homens em idade adulta predominavam. Advertimos que a plantation açucareira demandava uma quantidade maior de escravos especializados, quase sempre homens, o que não ocorria no Maranhão, dedicado ao algodão e arroz, com cultivo e beneficiamento relativamente mais simples.

TABELA 5

População de cor, por sexo, segundo condição jurídica

Paróquia N. S. do Rosário - 1801

\begin{tabular}{lcc}
\hline Condição jurídica & Homens & Mulheres \\
\hline Pretos & & \\
Livres & 123 & 125 \\
Cativos & 3.344 & 3.428 \\
\hline Mulatos & & \\
Livres & 2.093 & 2.075 \\
Cativos & 406 & 301 \\
\hline
\end{tabular}

Fonte: Biblioteca Pública Benedito Leite. Mapas estatísticos da capitania do Maranhão. São Luís (1801).

Outro dado que chama atenção refere-se à formação da família, mostrando que o casamento era significativo entre a população livre de cor, apesar de a maioria ser solteira. Os casados ou viúvos chegavam a $46,4 \%$, entre os pretos, e a $49,5 \%$, entre os mulatos.

Os dados da Tabela 6 comprovam que, poucas décadas após a inserção do Norte ao mercado agroexportador, já havia um segmento expressivo de alforriados de origem africana na região. Ainda que a maior proporção desses estava entre os mulatos, segmento relacionado à cor em que se classificaram os que não foram considerados "brancos" e "pretos" pelos párocos. Com certeza, entre os 4.168 "mulatos" livres estavam muitos mestiços de origens diversas, até mesmo índios ausentes, como afirmou o pároco. A quase paridade entre homens e mulheres (2.093 homens e 2.075 mulheres) reforça ainda mais nossa suposição, pois a historiografia sobre essa temática mostra que as mulheres sempre 
eram mais favorecidas nos casos de alforria. 0 alto índice dos casados e viúvos também nos leva a crer que não se tratasse de cativos recém-libertos, mas de moradores comuns da vila do Rosário, muitos deles mestiços de índio, contados pelo pároco como "mulatos livres".

TABELA 6

População livre de cor, por estado civil e sexo, segundo grupos etários Paróquia do Rosário - 1801

\begin{tabular}{|c|c|c|c|c|c|c|c|c|c|c|}
\hline \multirow{3}{*}{ Idades } & \multicolumn{5}{|c|}{ Pretos } & \multicolumn{5}{|c|}{ Mulatos } \\
\hline & \multirow{2}{*}{ Casados } & \multicolumn{2}{|c|}{ Solteiros } & \multicolumn{2}{|c|}{ Viúvos } & \multirow{2}{*}{ Casados } & \multicolumn{2}{|c|}{ Solteiros } & \multicolumn{2}{|c|}{ Viúvos } \\
\hline & & $\mathrm{H}$ & $M$ & $\mathrm{H}$ & $M$ & & $\mathrm{H}$ & M & $\mathrm{H}$ & M \\
\hline$(0-14)$ & 06 & 33 & 41 & 03 & 02 & 32 & 758 & 846 & 04 & 06 \\
\hline$(15-50)$ & 46 & 22 & 23 & 17 & 17 & 980 & 217 & 211 & 391 & 293 \\
\hline$(50 /+)$ & 10 & 04 & 02 & 05 & 09 & 212 & 50 & 22 & 61 & 35 \\
\hline Total & 62 & 67 & 66 & 25 & 28 & 1.224 & 1.025 & 1.079 & 456 & 384 \\
\hline
\end{tabular}

Fonte: Biblioteca Pública Benedito Leite. Mapas estatísticos da capitania do Maranhão. São Luís (1801).

A leitura da Tabela 6 também mostra que a porcentagem dos africanos libertos era pequena, apenas $5,87 \%$, geralmente dados como “pretos". Novamente, não verificamos um favorecimento das mulheres entre os pretos livres, mas sim daqueles menores de idade, provavelmente "crioulos", os nascidos em terras maranhenses que conseguiram alforrias por intermédio de seus pais.

Sobre a fecundidade das mulheres africanas e das supostamente afrodescendentes, aquelas dadas como “mulatas", observamos que a razão crianças/mulher ${ }^{3}$ entre as cativas alcançou o índice de 988, que não é alta, mas inferior à contabilizada entre as mulheres "pretas" e "mulatas" livres, que alcançou 1.373. Tal resultado confirma que as condições de cativeiro influíram nas taxas de fecundidade das mulheres. Consideramos aqui os intervalos de 0 a 10 anos para as crianças e de 15 a 50 anos para as mulheres, uma vez que os mapas dividiram a população em intervalos decimais.

Como já mencionado anteriormente, em 1802 a grande freguesia do Rosário foi desmembrada, surgindo a de N. S. das Dores do Itapecuru. Vinte anos depois, nos Mapas de 1821, a população das duas freguesias alcançava 23.282 habitantes, predominantemente composta pelos escravizados das plantations. Identificamos nos Mapas outro fenômeno social: a já significativa presença de alforriados residentes, tanto entre aqueles habitantes denominados "pretos", como entre os “mulatos".

Se considerarmos a alforria uma estratégia dos senhores para obter a colaboração dos escravizados, entendemos como importante o fato de $3 \%$ dos denominados "pretos" já terem conseguido sua liberdade, uma vez que a inserção ao mercado agroexportador havia começado há poucas décadas. Outro aspecto que chama atenção entre a população de cor na paróquia do Rosário é que havia uma oportunidade maior para os mulatos no alcance da alforria, pois apenas $2,98 \%$ dos considerados "pretos" a conseguiram, enquanto entre os mulatos essa porcentagem sobe para $85,49 \%$. Sempre lembrando que

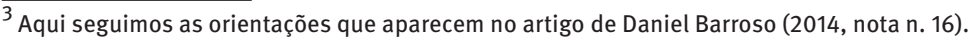


entre esses ditos "mulatos" podem estar outros estratos sociais com base na cor, como “índios dispersos", cafuzos, mamelucos, etc., que já eram livres ou libertos na segunda metade do século XVIII. Dado que comprova tal possibilidade é a relativa igualdade por sexo entre esses livres de cor: os homens "mulatos" livres chegavam a 50,22\%. Ora, estudos realizados em diversas regiões e conjunturas mostram que as alforrias favoreciam principalmente as mulheres. Mesmo assim, devemos mencionar que, entre aqueles considerados "pretos", também havia relativa igualdade entre homens (123) e mulheres (125) livres.

TABELA 7

População de cor, segundo condição jurídica

Paróquia N. S. do Rosário do Itapecuru - 1801

\begin{tabular}{lrc}
\hline Condição jurídica & N & $\%$ \\
\hline Pretos & & \\
Livres & 248 & 3,0 \\
$\quad$ Cativos & 8.054 & 97,0 \\
\hline Mulatos & & \\
$\quad$ Livres & 4.168 & 85,5 \\
Cativos & 707 & 15,5 \\
\hline
\end{tabular}

Fonte: Biblioteca Pública Benedito Leite. Mapas estatísticos da capitania do Maranhão. São Luís (1801).

Um caso que exemplifica os dados explanados é o do casal formado pelo sargento-mor Luiz Fernandes Ribeiro, natural de Mazagão, patriarcado de Lisboa, e Dona Joana Maria Freire Belfort, neta de um dos desbravadores da região. D. Joana morreu em 1803, aos 38 anos de idade, deixando cinco filhos, com idades entre 11 e dois anos. Como havia órfãos, foram inventariados todos os bens do casal, sendo possível saber que a família morava em São Luís, em uma construção térrea avaliada em 4:310\$000 (quatro contos, trezentos e dez mil réis). 0 casal vivia de sua propriedade rural localizada na Ribeira do Itapecuru, nas paragens Santa Izabel e Santa Ana, a maior parte composta por terras herdadas da família da senhora. Divididos em três faixas separadas, os domínios rurais, ainda que incluíssem uma "casa nova", foram avaliados em 2:760\$000 (dois contos, setecentos e sessenta mil réis), valor inferior ao da casa de morada em São Luís. Os 1.200 alqueires de arroz referidos no inventário foram avaliados em oitocentos e quarenta mil réis, sendo esta toda a produção avaliada no arrolamento (MOTA, 2012, p. 257).

No entanto, o item de maior valor apontado no inventário foi a escravaria, que totalizava 11:385\$000 (onze contos, trezentos e oitenta e cinco mil réis), composta por 57 pessoas, a maioria homens (54,3\%), sendo que os africanos sobressaíam: eram 39 , entre homens e mulheres, chegando a representar $63 \%$ do total. Tratava-se de um ajuntamento atípico, em que predominavam os adultos (entre 15 e 49 anos), alcançando $85 \%$. Os menores de 14 anos eram apenas sete, todos dados como "crioulos", filhos de africanos de primeira geração. Por outro lado, apenas três pessoas possuíam mais idade: o cativo Vicente, de nação mandinga, Domingas e Maria, ambas denominadas angola, todos na faixa dos 60 anos. 
Verificamos que 11 dos escravizados foram arrolados logo após a morada dos proprietários em São Luís; supondo-se que serviam a família na cidade, provavelmente foram contados na listagem referente à freguesia de Nossa Senhora da Vitória. 0 restante dos escravizados foi avaliado em meio às terras rurais, as ferramentas de trabalho e os rebanhos; portanto, eram os que labutavam na unidade produtiva às margens do rio do Itapecuru. Entre estes, aparece a indicação pelos comissários avaliadores de várias famílias cativas. Três delas composta por casal e filhos, como a formada por Manoel, de nação papel, e sua mulher Luzia, dada como angola. Seus filhos eram dois: Antônio de três anos e uma cria de peito. Alguns arranjos apresentavam esse perfil: pais e filhos, mas a maioria não alcançava esse ideal, pois quatro uniões entre os cativos se constituíam apenas do casal, outras três eram compostas da mãe e seu filho, como a encabeçada pela africana Ignês, papel, de 30 anos, e sua filha crioula Marcelina, ainda em tenra idade. Finalmente, foi registrada a família formada pelo africano "Portalis" (sic!), de 40 anos, e seu filho crioulo de 12. Nessa comunidade de cativos todos os lares traziam uma característica comum: a presença de pouquíssimos filhos, quase sempre um ou dois, podendo-se supor que ou haviam morrido ou os maiores de 14 anos seriam considerados mão de obra produtiva e constando separados de suas famílias. A família mais numerosa, formada por Vicente, mandinga, de 60 anos, e Violante, angola, de 40, conseguiu manter junto a si somente três filhos: Ramos e Gonçalo, de seis e cinco anos, e uma cria de peito. Talvez tenha almejado tal sorte devido à idade do africano, já um ancião. Quanto às mães cativas, percebemos que já eram mulheres maduras quando da maternidade, como a crioula Vicência, de 46 anos, arrolada juntamente com seu filho Alexandre de três anos. A mais jovem mãe encontrada nesse agrupamento era a angola Ana, de 26 anos, com uma cria de peito.

Finalmente, constatamos que a formação de laços familiares entre os companheiros de escravidão era uma realidade, pois quase $60 \%$ deles haviam estabelecido alguma espécie de parentesco, afim ou de sangue, tendo se tornado marido, mulher, filho ou filha de alguém.

\section{A população negra e de cor nos assentos de batismo da paróquia de N. S. das Dores do Itapecuru}

Como visto anteriormente, na paróquia de N. S. do Rosário do Itapecuru, onde foram contabilizados 8.761 escravos, entre "pretos" e "mulatos", 51\% eram casados ou viúvos, o que demonstra que a instituição do matrimônio na Igreja era disseminada entre essa população, com certeza devido ao forte trabalho missionário realizado pelas ordens religiosas, notadamente da Companhia de Jesus, na região Norte. Documentos que confirmam a formação de laços familiares entre os cativos são os registros de batismos da freguesia de N. S. das Dores do Itapecuru, desmembrada da freguesia do Rosário em 1802.

0 primeiro Livro de Registros encontrado para nova freguesia abrangeu o período de 1813 a 1825, mas está bastante danificado, sendo que foi possível recuperar apenas os 
assentos referentes aos dois primeiros anos, relativos a dois autos de "desobriga". ${ }^{4}$ Uma vez por ano os vigários eram obrigados a sair pela freguesia ministrando o sacramento do batismo, que nesse caso abrangia as margens do rio onde foram implantadas as primeiras unidades de cultivo de algodão e arroz. Nos anos mencionados, 1813 e 1814, o vigário Pedro Antônio Pereira Pinto do Lago batizou 367 crianças, das quais a maioria (338) em tenra idade e cativa, representando $92 \%$ do total! Portanto, o perfil étnico dos batizandos nessa freguesia corrobora os dados já mostrados em nossa investigação, pois o coadjutor registrou que $80 \%$ desses eram "pretos" e outros 16,34\% constam como "pardos", outra categoria ligada à cor utilizada na época que não aparece nos Mapas, nem nos Inventários post mortem, mas em inúmeras outras fontes do período. A designação "parda" refere-se à miscigenação, mas indica uma pele mais clara. Acreditamos que nos assentos de batismo a impressão do padre quanto à cor era mais visual; obviamente que se o batizando ainda que mestiço fosse livre, de família legítima e com bens, ele poderia omitir a cor, como vemos em inúmeros assentos.

Outro aspecto digno de nota na leitura dessa fonte reside no matrimônio, que era relativamente acessível mesmo à população negra ou "de cor”, pois $39 \%$ dos batizandos foram dados como filhos "legítimos”, ou seja, seus pais oficializaram a união junto à Igreja católica. Outra parte foi classificada como filhos "naturais", sendo que dez desses estavam acompanhados de seus pais na cerimônia, como registrou o coadjutor, talvez aguardando ocasião propícia para formalizar sua união, bastante comum de acontecer nas famílias de escravizados após o nascimento do primeiro filho (ARQUIVO PÚBLICO DO ESTADO DO MARANHÃO, 1813-14).

O vigário e seu ajudante, nos meses em que a chuva estiava, de agosto a dezembro, saíam ministrando o sacramento do batismo a seus fiéis. Nos dois anos mencionados, eles visitaram 142 propriedades, entre sítios e fazendas. No dia 5 de outubro de 1814 estiveram na Fazenda da Capoeirinha, onde batizaram sete crianças, todas em tenra idade, escravizadas e dadas como "pretas". 0 ajudante do vigário também anotou que quatro eram filhos naturais, sendo-lhes dados nomes cristãos: Anastácio, Matildes, Grinaldo e Bernarda. Suas mães eram mulheres solteiras e também escravas: Mônica, Felícia, Cizília e Izabel. Outras três meninas receberam os santos óleos nesse mesmo dia, mas nascidas em lares legítimos: Militana, Emília e Maria, esta última batizada em "perigo de vida”. Seus pais tiveram matrimônio sacramentado pela igreja católica; também eram escravos e com certeza africanos, pois todos foram dados como "pretos"; eram os casais André e Úrsula, Antônio e Apolônia, Manoel Antônio e Engrácia. Acreditamos que as cerimônias religiosas juntavam senhores aparentados ou vizinhos para cumprir suas obrigações junto à sociedade patriarcal, pois aparecem nos registros não somente

\footnotetext{
${ }^{4}$ Desobriga: incursão da igreja católica a regiões de difícil acesso, praticando a catequese e oferecendo os sacramentos a pagãos.
} 
o dono da propriedade, mas também outros senhores, nesse caso, o capitão Raimundo Ferreira Parga, o alferes Joaquim Ferreira de Assunção Parga e Francisco José Marques. Os padrinhos e madrinhas dos "escravinhos" eram quase sempre seus companheiros de escravidão, como Thereza Ângela e Breno, e alguns alforriados, como Alexandre, Raimundo e Anna, que apareciam dessa forma, sem o sobrenome. Também algumas pessoas livres tomaram afilhados cativos, como Alexandre Ferreira Lisboa, dona Ignês Raimunda Ferreira Lisboa e dona Gertrudes Ferreira Lisboa, talvez parentes ou vizinhos dos proprietários da fazenda.

A tipologia de fontes apresentadas nesse item, ainda que bastante limitada no que se refere ao cotidiano da comunidade formada a partir do trabalho nas unidades rurais, nos possibilita minimamente avançar no conhecimento dessas populações, notadamente em seus esforços de inserção social, de afirmação enquanto sujeitos.

\section{Considerações finais}

Com a inserção da região Norte ao comércio Atlântico, por meio da plantation escravista, ocorreram profundas mudanças no seu perfil demográfico, notadamente em algumas paróquias da capitania do Maranhão, que focalizamos nesse estudo. Variadas fontes indicam a introdução sob condição escrava de populações vindas do continente africano para trabalhar nas fazendas de algodão e arroz. Nesse período, foram levadas principalmente para a Ribeira do Itapecuru, onde a paróquia do Rosário se destacava pela concentração de cativos.

Os Mapas de 1798 e 1821 mostram que a população de cor predominava nas áreas de cultivo do algodão e arroz, chegando a quase $80 \%$ dos residentes. Essas populações, por sua vez, guardavam algumas particularidades em relação a outras áreas de plantation do Estado do Brasil, como, por exemplo, a razão de sexo, marcada pela quase paridade entre homens e mulheres, talvez devido à oferta do tráfico Atlântico para essa região.

As fontes notariais e eclesiásticas permitem que se conheça um pouco mais sobre a vida daqueles que foram trazidos para as Américas. Os inventários post mortem dos proprietários permitem que se conheçam o perfil das escravarias, sua composição do ponto de vista étnico, a formação de algumas famílias, entre outros aspectos. Mais ainda sabemos a partir dos assentos de batismo dos moradores dessa região, em que se observam as tentativas feitas pelos escravizados no intuito de se inserirem socialmente, seja por meio do casamento religioso ou do batismo de seus filhos. As relações patriarcais também continuaram a ser tecidas, pois muitos senhores se empenharam no sentido de que fossem ministrados os sacramentos cristãos a seus escravos, com certeza reunindo esforços no sentido de apaziguá-los, conformá-los à situação de cativeiro.

Finalmente, concluímos que todo esse processo mostra que a dinâmica populacional resulta das injunções econômicas, ainda mais em uma economia dependente como a colonial. 


\section{Referências}

ALENCASTRO, L. F. de. 0 trato dos viventes: formação do Brasil no Atlântico Sul. São Paulo: Companhia das Letras, 2000.

ARQUIVO DO TRIBUNAL DE JUSTIÇA DO MARANHÃO. Inventários post mortem avulsos (1785 a 1825). São Luís, MA, 1825.

. Inventário dos bens de Dona Joana Maria Freire Belfort. Seção de processos avulsos de inventário post mortem. São Luís, MA, 1804.

ARQUIVO PÚBLICO DO ESTADO DO MARANHÃO. Livro de Registro de Batismo da Freguesia de Nossa Senhora das Dores do Itapecuru. São Luís, MA, 1814.

. Livro de Testamentos (1763-1779). São Luís, 1779. (Manuscrito).

ARRUDA, J. J. de A. O Brasil no comércio colonial. São Paulo: Ática, 1980.

ASSUNÇÃO, M. R. De caboclos a bem-te-vis: formação do campesinato numa sociedade escravista, Maranhão (1800-1850). São Paulo: AnnaBlume, 2015.

BARROSO, D. S. Múltiplos do cativeiro: casamento, compadrio e experiência comunitária numa propriedade escrava no Grão-Pará (1840-1870). Afro-Ásia, São Paulo, n. 50, p. 93-128, 2014.

BARROSO JR., R. dos S. Nas rotas do Atlântico equatorial: tráfico de escravos rizicultores da Alta-Guiné para o Maranhão (1770-1800). 2009. 119f. Dissertação (Mestrado em História) - Programa de Pós-Graduação em História, Universidade Federal da Bahia, Salvador, 2009.

BIBLIOTECA PÚBLICA BENEDITO LEITE. Mapas estatísticos da capitania do Maranhão. São Luís: Secretaria de Cultura do Estado do Maranhão, 1801.

BOXER, C. 0 império marítimo português (1415-1825). Tradução de Ana Olga de Barros Barreto. São Paulo: Companhia das Letras, 2002.

HAWTHORNE, W. From Africa to Brazil: culture, identity, and an Atlantic slave trade, 1600-1830. Cambridge: Cambridge University Press, 2010.

KARASCH, M. "Minha nação": identidades escravas no fim do Brasil colonial. In: SILVA, M. B. N. da (Org.). Brasil: colonização e escravidão. Rio de Janeiro: Nova Fronteira, 2000.

MARQUES, C. A. Dicionário histórico e geográfico da Província do Maranhão. Rio de Janeiro: Fon-Fon e Seleta, 1970.

MOTA, A. S.; BARROSO, D. S. Economia e demografia da escravidão no Maranhão e no Grão-Pará: uma análise comparativa da estrutura da posse de cativos (1785-1850). Revista de História (São Paulo), n.176, 2017.

MOTA, S. A. Família escrava nas plantations do Maranhão: demografia e sociabilidades. In: GALVES, M. C.; COSTA, Y. O Maranhão oitocentista. São Luís: Editora UEMA; Café \& Lápis, 2015.v. 1.

. As famílias principais: redes de poder no Maranhão colonial. São Luís: Edufma, 2012.

NADALIN, S. O. História e demografia: elementos para um diálogo. Campinas: Abep, 2004.

REIS, J. J. Rebelião escrava no Brasil em 1835: a história do levante dos malês em 1835. São Paulo: Companhia das Letras, 2003.

RIBEIRO, F. P. Memórias dos sertões maranhenses: reunidas aos cuidados de Manoel de Jesus de Barros Martins. São Paulo: Siciliano, 2002.

SERRÃO, J. V. O quadro humano. In: SERRÃO, J. V.; MATTOSO, J.; HESPANHA, A. M. (Coord.). História de Portugal. Lisboa: Editorial Estampa, 1998. v. 4. 


\title{
Sobre as autoras
}

Antonia da Silva Mota tem pós-doutorado em Demografia Histórica pelo Núcleo de Estudos de População "Elza Berquó", Universidade Estadual de Campinas (Nepo/Unicamp), é doutora e mestre em História pela Universidade Federal de Pernambuco (UFPE). Professora associada do Departamento de História da Universidade Federal do Maranhão (UFMA).

Maísa Faleiros da Cunha tem pós-doutorado na Faculdade de Economia, Administração e Contabilidade da Universidade de São Paulo (FEA/USP), é doutora e mestre pela Universidade Estadual de Campinas (Unicamp). Pesquisadora do Núcleo de Estudos de População "Elza Berquó", Universidade Estadual de Campinas (Nepo/Unicamp).

\section{Endereço para correspondência}

\author{
Antonia da Silva Mota \\ UFMA - Universidade Federal do Maranhão \\ Centro de Ciências Humanas \\ Av. dos Portugueses, 1966 - Cidade Universitária Dom Delgado \\ 65000-000 - São Luís-MA, Brasil \\ Maísa Faleiros da Cunha \\ Unicamp - Universidade Estadual de Campinas \\ Núcleo de Estudos de População "Elza Berquó" \\ Av. Albert Einstein, 1300 - Cidade Universitária Zeferino Vaz \\ 13081-970 - Campinas-SP, Brasil
}

\begin{abstract}
At the Core of Africanization: Black and Colored People in Population Maps of Colonial Maranhão, Brazil (1798-1821)

The study analyzes the demographic boom of African slave populations in the plantation areas from the Mapas de População of Maranhão. In particular, we focus on the parish of Rosário do Itapecuru using other sources - post-mortem inventories and parish baptismal records. The maps from 1798 and 1821 made it possible to evidence the gender, age, ethnicity and legal status of the resident population as well as show the importance of slave population in cotton and rice crop areas, reaching almost $80 \%$ of residents. These populations, in turn, presented certain peculiarities in relation to other plantation areas in the State of Brazil, such as the sex ratio marked by the almost parity between men and women.
\end{abstract}

Keywords: Slavery. Statistical population maps. Maranhão. Brazil.

\section{Resumen}

En el núcleo de africanización: pueblo negro y de color en los mapas de población del Maranhão colonial, Brasil (1798-1821)

El estudio analiza el boom de las poblaciones esclavas de origen africano en las áreas de plantación a partir de los Mapas Estadísticos de Maranhão. En particular, nos centramos en la parroquia Rosario del Itapecurú utilizando otras fuentes documentales: inventarios post mortem 
y registros parroquiales de bautismo. Los mapas de 1798 y 1821 posibilitaron evidenciar el perfil sexual, la edad, la condición étnica y jurídica de la población residente y muestran la importancia de la población esclava en las áreas de cultivo de algodón y de arroz, que llega a casi $80 \%$ de los residentes. Estas poblaciones mantenían a su vez algunas peculiaridades en relación con otras áreas de plantación del Estado de Brasil, por ejemplo, la proporción de sexos marcada por la casi paridad entre hombres y mujeres.

Palabras clave: Esclavitud. Mapas de población. Maranhão.

Recebido para publicação em 31/01/2017

Aceito para publicação em 15/08/2017 